\title{
The added value of 18 F-FDG PET/CT in staging non-small cell lung cancer
}

\author{
Aliaa S. Sheha*, Remon Zaher Elia and Nada Mohammed Farid Hassan Ghoneim
}

\begin{abstract}
Background: Non-small cell lung cancer (NSCLC) accounts for about $80 \%$ of all lung cancers. The current criteria for its staging are based on the TNM system that determines treatment options and predicts survival rate in patients. The aim of the study was to evaluate the diagnostic accuracy of 18F-fluorodeoxyglucose (18F-FDG) positron emission tomography PET/CT in staging of NSCLC patients.

Methods: A retrospective study was conducted. We reviewed the CT and PET/CT examinations done in our institution on pathologically proven patients of NSCLC, in the period between October 2018 and end of July 2019.

Results: A total of 40 patients were evaluated with the age ranging from 37 to 77 years old, and the mean was 55.63 years (SD \pm 10.29). There were 31 male cases and 9 female cases. When we compared contrast enhanced CT (CECT) to PET-CT for staging, PET-CT helped upstage disease in 10 of 40 patients (25\%) and downstage in 3 of 40 patients (7.5\%).

Conclusion: PET/CT is a useful imaging tool in initial staging of the newly diagnosed patients with NSCLC. It is better than $\mathrm{CT}$ alone for detection of malignant lesions for accurate staging. It can change the strategy of treatment according to its findings.
\end{abstract}

Keywords: Non-small cell, Lung cancer, PET/CT

\section{Background}

The optimal treatment of non-small cell lung cancer (NSCLC) relies on accurate disease staging that is based on the TNM system which relies on tumor size, regional nodal involvement, and the presence of metastasis [1]. Correct evaluation of the presence or absence of metastases in mediastinal and hilar lymph nodes is a critical factor that may determine operability and long-term survival in patients with NSCLC. Surgical treatment can be expected in $70 \%$ of patients with N0 stage and up to $24 \%$ of patients with N2 stage; however, surgery is generally not indicated in patients with N3 stage cancer [2]. Unfortunately, only $25 \%$ of patients will have resectable disease at presentation. Of those with stage I and II disease, 20 and $40 \%$, respectively, will ultimately relapse with metastatic disease that was occult at the time of presentation [3]. Although X-ray chest radiograph is simple and convenient, its high rate of missed diagnosis

\footnotetext{
* Correspondence: aliaa_sheha@yahoo.com

Radiodiagnosis Department, Faculty of Medicine, Ain Shams University, Cairo, Egypt
}

makes the credibility of clinical diagnosis low [4]. With the continuous development of medical research and clinical treatment level, multi-slice spiral CT imaging diagnosis technology is widely used in clinical diagnosis of malignant tumors [5]. Although it provides anatomic information, it has poor sensitivity (approximately 50\%) and specificity (approximately 85\%) for detecting mediastinal tumor [6]. 18F-fluorodeoxyglucose (18F-FDG) positron emission tomography (PET) images may be more sensitive than CT because alterations in tissue metabolism generally precede anatomical changes [7]. However, PET has relatively poor spatial resolution, thus limits its anatomical localization of lesions [8]. Integrated PET-CT provides information about anatomy and metabolism by combining morphological CT data and functional PET data [9]. 18F-FDG PET/CT scanning is now a standard procedure for staging patients with nonsmall cell lung cancer (NSCLC) and therefore is implemented in various international guidelines for presurgical evaluation [10]. 


\section{Aim of work}

The aim of the study is to evaluate the diagnostic accuracy of 18F-FDG PET/CT in staging of NSCLC patients.

\section{Methods}

This retrospective study included a total of 40 patients pathologically proven to have NSCLC at Radiology Department in our institution from October 2018 till July 2019. The CT and PET/CT studies of 50 patients with pathologically proven NSCLC were reviewed. Both sexes were included with no age predilection. Ten patients were excluded because they were on chemotherapy with no pretreatment studies were found in our records. The institutional review board waived the requirement for informed patient consent.

\section{Study procedures}

In our institution, specific information is required for optimal interpretation of CECT and FDG PET/CT images, such as clinical history; results of previous imaging studies; history of surgery, chemotherapy, or radiation therapy; and the presence of a central venous or drainage catheter. The patients fasted for at least $4-6 \mathrm{~h}$ before the study, but drank water to maintain good hydration. The fasting blood glucose level was measured prior to 18F FDG injection, with the preferred level being lower than $200 \mathrm{mg} / \mathrm{dl}$.

\section{Technique}

While resting on a reclining chair, the patients received $(0.8 \mathrm{mCi} / 10 \mathrm{~kg})$ of $18 \mathrm{~F}-\mathrm{FDG}$ intravenously and were asked to drink water with no excessive movement or talking. The imaging sequences were taken 45-60 min after tracer injection. All patients were positioned on the imaging table with their arms up. After determining the imaging field (base of skull to mid thighs) with an initial scout scan, CT acquisition with intravenous contrast material (Ultravist) $(1-2 \mathrm{ml} / \mathrm{kg}$ ) was performed (28-30 mAs; $120 \mathrm{Kv}$; slice thickness $5 \mathrm{~mm}$ ). The CT scan was followed by the PET emission scan. Interpretation of the CECT was done first by two independent readers, and the interpretation of PET/CT was done after the CT and comparison of the results was done. Discrepancies between the readers were resolved by consensus. The cases were staged according to the TNM staging. (Table 1) [11].

\section{Statistical analysis}

Data was analyzed statistically and entered to the Statistical Package for Social Science (IBM SPSS) version 23, and all the results were tabulated, presented graphically, and will be interpreted and discussed.

\section{Results}

A total of 40 patients who were pathologically proven to have NSCLC were included in the study. There were 31 male cases (77.5 \%) and 9 female cases (22.5\%). Histological types are 21 cases (52.5\%) of adenocarcinoma, 12 cases $(30 \%)$ of squamous cell carcinoma, and 7 cases (17.5\%) of large cell carcinoma.

All 40 patients underwent baseline contrast-enhanced CT (CECT) and PET-CT for staging. When we compared CECT against PET-CT for staging, PET-CT helped in upstaging the disease in 10 out of 40 patients (25\%) and downstaging disease in only 3 patients (7.5 $\%)$. The staging was not changed in 27 cases (67.5\%).

Comparison of CECT and PET-CT was done. Table 2 presents the local extension of tumors ( $\mathrm{T}$ stage) by $\mathrm{CT}$ versus PET-CT. Lymph node involvement by the tumors ( $\mathrm{N}$ stage) is illustrated in Table 3. The $\mathrm{M}$ stage of the tumors is shown in Table 4.

In this study, stages I-A to III-A of the disease were considered as operable cases and stages III-B and IV were considered as inoperable cases. This means that PET-CT converted 2 cases from being inoperable to being operable (one case from IVA to IB, the other case from IIIB to IIB) and converted three patients from being operable by $\mathrm{CT}$ to being inoperable by PET/CT (two cases from IIIA to IVA and IVB and the last case from IIIA to IIIB). This indicates that PET-CT changed the plan of treatment in 5 patients.

\section{Discussion}

Correct staging of lung cancer is important because the treatment options and prognosis differ significantly according to stage. Understanding the advantages and disadvantages of the available methods for staging NSCLC is crucial to decision-making [10].

\section{According to T staging}

As regards chest wall and mediastinal invasion, in the current study, there was no mismatch between CT and PET -CT. This disagrees with Lardinois et al. [12] and De Wever et al. [13] who concluded that integrated $\mathrm{PET} / \mathrm{CT}$ correctly predicted the $\mathrm{T}$ staging in patients with NSCLC in $86 \%$ of cases versus $68 \%$ with CT.

However, in this study, PET/CT allowed better discrimination between the tumor and the surrounding consolidative changes. This agrees with the study by De Wever et al. [13] who stated that PET/CT more accurately determined the $\mathrm{T}$ designation compared with $\mathrm{CT}$ alone. One of the advantages of PET/CT is in differentiating central tumors from post obstructive atelectasis because the tumor will often have increased FDG uptake compared with an atelectatic lung.

Regarding ipsilateral pulmonary nodules, this study revealed a mismatch between $\mathrm{CT}$ and PET-CT, with $\mathrm{CT}$ 
Table 1 Eighth edition of TNM staging of lung cancer [11]

\begin{tabular}{|c|c|c|}
\hline Category or stage & Descriptor & 5 -year survival rate (\%) \\
\hline \multicolumn{3}{|l|}{ T category } \\
\hline TX & Tumor in sputum and/or bronchial washings, not assessed at imaging or bronchoscopy & \\
\hline T0 & No evidence of primary tumor & \\
\hline Tis & Carcinoma in situ & $\ldots$ \\
\hline $\mathrm{T} 1$ & $\leq 3 \mathrm{~cm}$ in longest axis & $\ldots$ \\
\hline $\mathrm{T} 1 \mathrm{a}(\mathrm{mi})$ & Minimally invasive adenocarcinoma & $\ldots$ \\
\hline T1a & $\leq 1 \mathrm{~cm}$ in the longest axis & 92 \\
\hline $\mathrm{T} 1 \mathrm{~b}$ & $>1$ to $\leq 2 \mathrm{~cm}$ in the longest axis & 83 \\
\hline T1c & $>2$ to $\leq 3 \mathrm{~cm}$ in the longest axis & 76 \\
\hline $\mathrm{T} 2$ & $\begin{array}{l}>3 \text { to } \leq 5 \mathrm{~cm} \text { in the longest axis; involves the main bronchus, visceral pleura, or atelectasis or obstructive } \\
\text { pneumonitis extending to the hilum }\end{array}$ & 67 \\
\hline T2a & $>3$ to $\leq 4 \mathrm{~cm}$ in the longest axis & 67 \\
\hline $\mathrm{T} 2 \mathrm{~b}$ & $>4$ to $\leq 5 \mathrm{~cm}$ in the longest axis & 60 \\
\hline $\mathrm{T} 3$ & $\begin{array}{l}>5 \text { to } \leq 7 \mathrm{~cm} \text { in the longest axis; invades the chest wall, phrenic nerve, or parietal peri-cardium; or nod- } \\
\text { ule in the same lobe as the primary tumor }\end{array}$ & 52 \\
\hline T4 & $\begin{array}{l}>7 \mathrm{~cm} \text { in the longest axis; invades the diaphragm, mediastinum, carina, trachea, heart, great vessels, } \\
\text { recurrent laryngeal nerve, esophagus, or vertebral body; nodule in different ipsilateral lobes }\end{array}$ & 38 \\
\hline \multicolumn{3}{|l|}{ N category } \\
\hline NO & No regional nodal metastases & 75 \\
\hline N1 & Metastasis in ipsilateral peribronchial or hilar nodes or intrapulmonary nodes & 49 \\
\hline N2 & Metastasis in ipsilateral mediastinal nodes or subcarinal nodes & 36 \\
\hline N3 & $\begin{array}{l}\text { Metastasis in contralateral mediastinal, contralateral hilar, ipsilateral or contralateral scalene, or } \\
\text { supraclavicular nodes }\end{array}$ & 20 \\
\hline \multicolumn{3}{|l|}{ M category } \\
\hline MO & No distant metastasis & \\
\hline M1a & $\begin{array}{l}\text { Tumor nodule in contralateral lung; tumor with pleural or pericardial nodules or malignant pleural or } \\
\text { pericardial effusion }\end{array}$ & 11.4 \\
\hline M1b & Solitary single-organ extrathoracic metastasis & 11.4 \\
\hline M1c & Multiple extrathoracic metastases in one or multiple organs & 6.3 \\
\hline \multicolumn{3}{|l|}{ Stage group } \\
\hline Stage |A 1 & T1a(mi)No M0, T1aNoMo & 92 \\
\hline Stage IA2 & T1bNOMO & 83 \\
\hline Stage IA3 & T1CNOMO & 77 \\
\hline Stage IB & T2aNOMO & 68 \\
\hline Stage IIA & T2bNOMO & 60 \\
\hline Stage $\| B$ & T1aN1M0, T1bN1M0, T1cN1M0, T2aN1M0, T2bN1M0, T3NOMO & 53 \\
\hline Stage IIIA & T1aN2M0, T1bN2M0, T1cN2M0, T2aN2MO, T2bN2MO, T3N1M0, T4 NO MO,T4N1MO & 36 \\
\hline Stage IIIB & T1aN3M0, T1bN3M0, T1cN3M0, T2aN3M0, T2bN3M0, T3N2M0, T4N2M0 & 26 \\
\hline Stage IIIC & T3N3MO, T4N3M0 & 13 \\
\hline Stage IVA & Any $\mathrm{T}$, any $\mathrm{N}, \mathrm{M} 1 \mathrm{a}$; any $\mathrm{T}$, any $\mathrm{N}, \mathrm{M} 1 \mathrm{~b}$ & 10 \\
\hline Stage IVB & Any $\mathrm{T}$, any $\mathrm{N}, \mathrm{M} 1 \mathrm{C}$ & 0 \\
\hline
\end{tabular}

having false positive results in 9 cases. This caused PETCT to downstage some patients. This is in keeping with the studies by Yi et al. [14] and Halley et al. [15],who concluded that PET-CT showed high sensitivity and specificity in differentiating benign from malignant pulmonary nodules more than $1 \mathrm{~cm}$. It is also concordant with the study by Acker and Burrell [16] who stated that patients with negative (i.e. No FDG uptake) PET-CT nodules only need a follow-up. Among the cases downstaged with PET$\mathrm{CT}$, in only 1 case, the overall stage was changed and the 
Table 2 Showing local extension of the tumor by CT versus PET-CT

\begin{tabular}{|c|c|c|c|c|c|c|c|c|}
\hline & & \multicolumn{2}{|l|}{$C T$} & \multicolumn{2}{|l|}{ PET } & \multirow{2}{*}{$\begin{array}{l}\text { P. } \\
\text { diff. }\end{array}$} & \multirow{2}{*}{$\begin{array}{l}\text { P. } \\
\text { agree. }\end{array}$} & \multirow[t]{2}{*}{ Kappa aggr. 95\% Cl } \\
\hline & & No. & $\%$ & No. & $\%$ & & & \\
\hline \multirow[t]{2}{*}{ Chest wall invasion } & Positive & 4 & 10.0 & 4 & 10.0 & 1.000 & 0.000 & 1.000 (1.000 to 1.000$)$ \\
\hline & Negative & 36 & 90.0 & 36 & 90.0 & & & \\
\hline \multirow[t]{2}{*}{ Mediastinal invasion } & Positive & 14 & 35.0 & 14 & 35.0 & 1.000 & 0.000 & $1.000(1.000$ to 1.000$)$ \\
\hline & Negative & 26 & 65.0 & 26 & 65.0 & & & \\
\hline \multirow[t]{2}{*}{ Ipsilateral pulmonary nodules } & Positive & 18 & 45.0 & 9 & 22.5 & 0.033 & 0.000 & 0.524 (0.283 to 0.765$)$ \\
\hline & Negative & 22 & 55.0 & 31 & 77.5 & & & \\
\hline \multirow[t]{2}{*}{ Diaphragmatic invasion } & Positive & 0 & 0.0 & 0 & 0.0 & 1.000 & 0.000 & - \\
\hline & Negative & 40 & 100.0 & 40 & 100.0 & & & \\
\hline \multirow[t]{2}{*}{ Recurrent laryngeal nerve invasion } & Positive & 1 & 2.5 & 4 & 10.0 & 0.166 & 0.002 & $0.375(-0.156$ to 0.906$)$ \\
\hline & Negative & 39 & 97.5 & 36 & 90.0 & & & \\
\hline \multirow[t]{2}{*}{ Pleural invasion } & Positive & 3 & 7.5 & 5 & 12.5 & 0.456 & 0.000 & 0.724 (0.366 to 1.000$)$ \\
\hline & Negative & 37 & 92.5 & 35 & 87.5 & & & \\
\hline
\end{tabular}

patient became operable. In the remaining 8 cases, the overall stage was the same due to nodal and distant metastasis.

A study by $\mathrm{Ma} C$ et al. [17] reported the ability of PET-CT to detect recurrent laryngeal nerve invasion and to clarify the cause of associated hoarseness of voice in lung cancer patients. This is concordant with the current study, where PET-CT detected 4 cases of recurrent laryngeal nerve invasion, but $\mathrm{CT}$ detected only one case. However, on retrospective pattern, the invasion could be detected by CT. At FDG PET/CT, unilateral vocal cord paralysis appeared as asymmetric increased uptake in the normal cord due to compensation by and hypertrophy of the non-paralyzed muscles (Fig. 1). On retrospective analysis of the CT, vocal cord paralysis was demonstrated as ipsilateral piriform sinus dilatation and medial rotation and thickening of the aryepiglottic fold.

Regarding the 3 cases of recurrent laryngeal nerve paralysis upstaged by PET-CT, their overall stage remained the same, due to nodal and distant metastasis in two cases. The remaining one showed no change and was staged as T4 according to tumor size.

\section{According to $\mathbf{N}$ staging}

Accurate mediastinal lymph node staging is particularly important, as in many cases, the status of these nodes will determine whether surgical resection of lung cancer is possible [18].

This study agrees with Darling et al. [19] and Perigaud et al. [20] that PET-CT is a valuable tool in mediastinal lymph node staging but it should be considered as a

Table 3 Showing the sites of lymph node groups involvement in CT versus PET-CT

\begin{tabular}{|c|c|c|c|c|c|c|c|c|}
\hline & & \multicolumn{2}{|l|}{$\mathrm{CT}$} & \multicolumn{2}{|l|}{ PET } & \multirow{2}{*}{$\begin{array}{l}\text { P. } \\
\text { diff. }\end{array}$} & \multirow{2}{*}{$\begin{array}{l}\text { P. } \\
\text { agree. }\end{array}$} & \multirow[t]{2}{*}{ Kappa } \\
\hline & & No. & $\%$ & No. & $\%$ & & & \\
\hline \multirow[t]{2}{*}{ Ipsilateral hilar } & Positive & 11 & 27.5 & 23 & 57.5 & 0.007 & 0.001 & $0.438(0.218$ to 0.658$)$ \\
\hline & Negative & 29 & 72.5 & 17 & 42.5 & & & \\
\hline \multirow[t]{2}{*}{ Ipsilateral mediastinal } & Positive & 23 & 57.5 & 28 & 70.0 & 0.245 & 0.006 & 0.415 (0.135 to 0.695$)$ \\
\hline & Negative & 17 & 42.5 & 12 & 30.0 & & & \\
\hline \multirow[t]{2}{*}{ Subcarinal } & Positive & 5 & 12.5 & 15 & 37.5 & 0.010 & 0.902 & $0.015(-0.232$ to 0.262$)$ \\
\hline & Negative & 35 & 87.5 & 25 & 62.5 & & & \\
\hline \multirow[t]{2}{*}{ Contralateral hilar } & Positive & 2 & 5.0 & 7 & 17.5 & 0.077 & 0.002 & $0.398(0.00334$ to 0.792$)$ \\
\hline & Negative & 38 & 95.0 & 33 & 82.5 & & & \\
\hline \multirow[t]{2}{*}{ Contralateral mediastinal } & Positive & 4 & 10.0 & 7 & 17.5 & 0.330 & 0.000 & $0.688(0.364$ to 1.000$)$ \\
\hline & Negative & 36 & 90.0 & 33 & 82.5 & & & \\
\hline \multirow[t]{2}{*}{ Supraclavicular } & Positive & 3 & 7.5 & 5 & 12.5 & 0.456 & 0.003 & $0.448(0.000459$ to 0.896$)$ \\
\hline & Negative & 37 & 92.5 & 35 & 87.5 & & & \\
\hline
\end{tabular}


Table 4 Showing the sites of distant metastases by $C T$ versus PET-CT

\begin{tabular}{|c|c|c|c|c|c|c|c|c|}
\hline & & \multicolumn{2}{|l|}{ CT } & \multicolumn{2}{|l|}{ PET } & \multirow{2}{*}{$\begin{array}{l}\text { P. } \\
\text { diff. }\end{array}$} & \multirow{2}{*}{$\begin{array}{l}\text { P. } \\
\text { agree. }\end{array}$} & \multirow[t]{2}{*}{ Kappa } \\
\hline & & No. & $\%$ & No. & $\%$ & & & \\
\hline \multirow[t]{2}{*}{ Contalateral nodules } & Positive & 9 & 22.5 & 3 & 7.5 & 0.060 & 0.001 & 0.437 (0.0932 to 0.780$)$ \\
\hline & Negative & 31 & 77.5 & 37 & 92.5 & & & \\
\hline \multirow[t]{2}{*}{ Pleural effusion } & Positive & 10 & 25.0 & 3 & 7.5 & 0.034 & 0.083 & $0.217(-0.0999$ to 0.535$)$ \\
\hline & Negative & 30 & 75.0 & 37 & 92.5 & & & \\
\hline \multirow[t]{2}{*}{ Liver mets } & Positive & 7 & 17.5 & 5 & 12.5 & 0.531 & 0.000 & 0.805 (0.546 to 1.000$)$ \\
\hline & Negative & 33 & 82.5 & 35 & 87.5 & & & \\
\hline \multirow[t]{2}{*}{ Adrenal mets } & Positive & 3 & 7.5 & 4 & 10.0 & 0.692 & 0.000 & 0.844 (0.545 to 1.000$)$ \\
\hline & Negative & 37 & 92.5 & 36 & 90.0 & & & \\
\hline \multirow[t]{2}{*}{ Bone mets } & Positive & 7 & 17.5 & 13 & 32.5 & 0.121 & 0.000 & 0.612 (0.348 to 0.876$)$ \\
\hline & Negative & 33 & 82.5 & 27 & 67.5 & & & \\
\hline \multirow[t]{2}{*}{ Intramuscular mets } & Positive & 1 & 2.5 & 4 & 10.0 & 0.166 & 0.002 & $0.375(-0.156$ to 0.906$)$ \\
\hline & Negative & 39 & 97.5 & 36 & 90.0 & & & \\
\hline \multirow[t]{2}{*}{ Brain mets } & Positive & 2 & 5.0 & 2 & 5.0 & 1.000 & 0.000 & 1.000 (1.000 to 1.000$)$ \\
\hline & Negative & 38 & 95.0 & 38 & 95.0 & & & \\
\hline \multirow[t]{2}{*}{ Abdominal LNs } & Positive & 3 & 7.5 & 7 & 17.5 & 0.176 & 0.000 & 0.553 (0.181 to 0.925$)$ \\
\hline & Negative & 37 & 92.5 & 33 & 82.5 & & & \\
\hline \multirow[t]{2}{*}{ Pancreatic mets } & Positive & 1 & 2.5 & 1 & 2.5 & 1.000 & 0.000 & 1.000 (1.000 to 1.000$)$ \\
\hline & Negative & 39 & 97.5 & 39 & 97.5 & & & \\
\hline
\end{tabular}

good negative modality and when positive mediastinal lymph nodes are detected, invasive mediastinal staging must be performed. Multiple studies Wever et al. [21], Lardinois et al. [12], Jeon et al. [22], Liu et al. [23], and Yang et al. [24] reported that PET-CT is more accurate than PET or CT alone in mediastinal lymph node staging.

In the current study, PET-CT upstaged 2 cases with ipsilateral hilar LNs, 4 cases with ipsilateral mediastinal LNs, 3 cases with contralateral LNs (Fig. 2) and 1 case with supraclavicular LNs. It downstaged 3 cases with ipsilateral mediastinal LNs. In each group, there were cases with no overall change in stage due to other findings.

\section{According to $\mathrm{M}$ staging}

Regarding contralateral pulmonary nodules detected only by CT, all the six cases showed no change in overall staging and were still staged as M1c due to the presence of distant metastasis.

Pleural effusions are common in patients with NSCLC. Many of these pleural effusions are benign and may represent benign reactive fluid collections that do not preclude curative surgery. Thus, it is important to accurately differentiate benign from malignant effusion [25].

This study agrees with Schaffler et al. [26] who reported that that PET-CT is a good tool for differentiation between benign and malignant pleural effusion. In

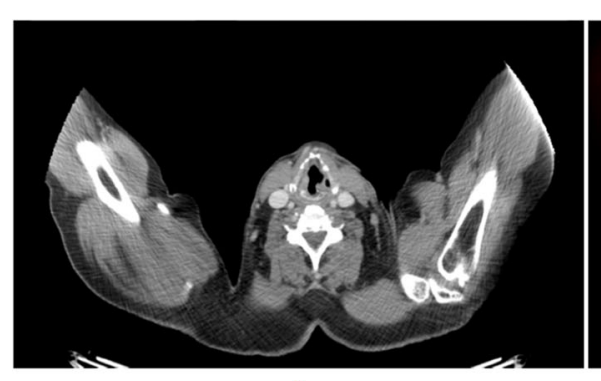

A.

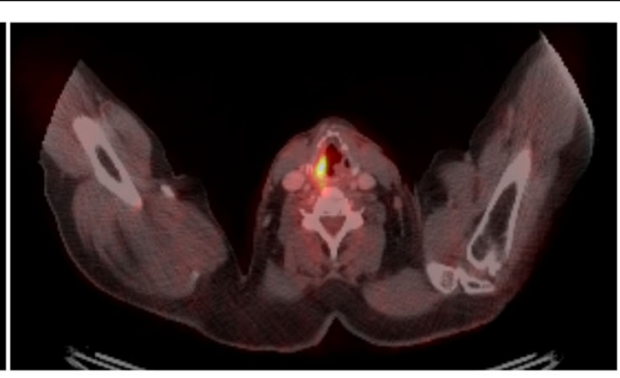

B.

Fig. 1 A 67-year-old male patient, pathologically proven having NSCLC; the initial staging revealed the following: a CECT failed to detect clearly the left recurrent laryngeal nerve paralysis and invasion and $\mathbf{b}$ PET/CT showed high-grade metabolic activity at the right vocal cord due to paralysis of the left recurrent laryngeal nerve denoting its invasion 


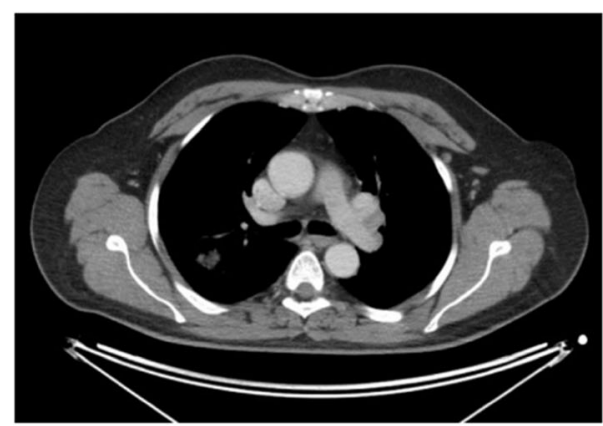

A.

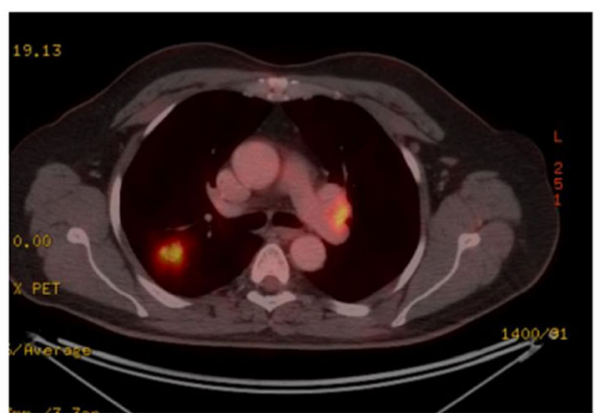

B.

Fig. 2 A 58-year-old male patient, pathologically proven having NSCLC; the initial staging revealed the following: a CECT showed only ipsilateral hilar LNs, b PET/CT detected contralateral hilar LN with high FDG (SUV =6) and upstaged the patient from N2 to N3

this study, PET/CT downstaged only one case from M1a to M0 as the pleural effusion was not FDG avid, while the remaining cases showed no change in $M$ stage due to the presence of distant metastasis.

In routine clinical practice, $\mathrm{CT}$ remains the standard imaging technique for the liver. The use of PET is mainly to provide additional information for the differentiation of hepatic lesions that are indeterminate on conventional imaging [27].

This study agrees with Stroobants [27] that PET-CT provides additional information for the characterization of hepatic lesions detected by CT. PET/CT led to downstaging of two cases, one of them was downstaged from M1b to M0 and from IVA to IB rendering the patient operable, yet the bad general condition of the patient precluded surgery. The other case was downstaged from M1b to M1a, but the overall stage was not changed (IVA) due to the associated contralateral pulmonary nodules.

Regarding adrenal metastasis, Fangfang and Hong [28] showed that in patients with NSCLC, many solitary adrenal masses were not malignant. So, it is very critical to distinguish between a metastatic lesion and an adenoma.
In this study, PET/CT upstaged only one case from M0 to M1b and from IIIc to IV A after detecting high FDG uptake in the adrenal gland (Fig. 3).

Regarding brain metastasis, in this study, only two cases had brain metastasis by CT and were identified easily by PET-CT because of the good anatomical localization applied by CT. This study agrees with Fangfang and Hong [28] and Patricia et al. [29] that CT and/ or MRI are more sensitive than PET/CT in detecting brain metastasis. So, there was no change in the staging regarding brain metastasis in this study.

Regarding bone metastasis, in the current study, we agree with Silvestri et al. [6], Wu et al. [30], and Schirrmeister et al. [31] studies who concluded that PET-CT is effective in detecting bone metastasis. In this study, PET/CT upstaged 4 cases from M0 and M1a to M1b but two cases showed no change due to associated extrathoracic metastasis (Fig. 4).

Regarding intramuscular metastasis, this study agrees with Surov et al. [32], Yilmaz et al. [33], and Savas et al. [34] who reported high sensitivity and specificity of $\mathrm{PET} / \mathrm{CT}$ to detect intramuscular metastasis in comparison to CT alone. In the current study, the three cases

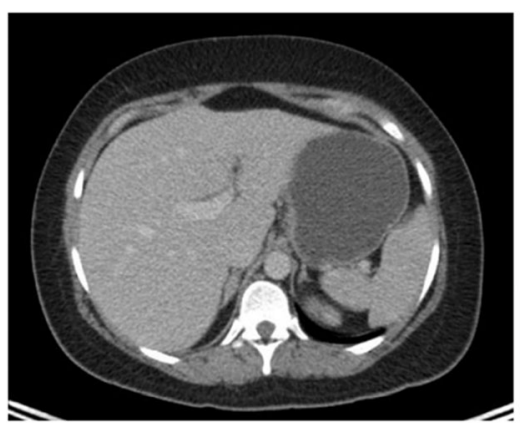

A.

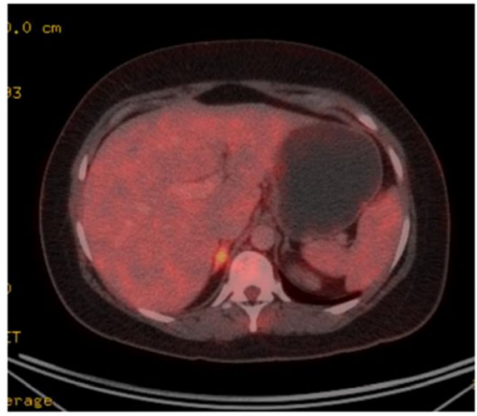

B.

Fig. 3 A 37-year-old female patient, pathologically proven having NSCLC; the initial staging showed a CECT revealed normal radiographic features of right adrenal gland and the patient was staged as MO and III B, and $\mathbf{b}$ PET/CT showed high FDG uptake in the right adrenal gland $(S U V=10)$ indicating adrenal metastasis and the patient was upstaged from M0 to M1b and from IIIB stage to IVA 


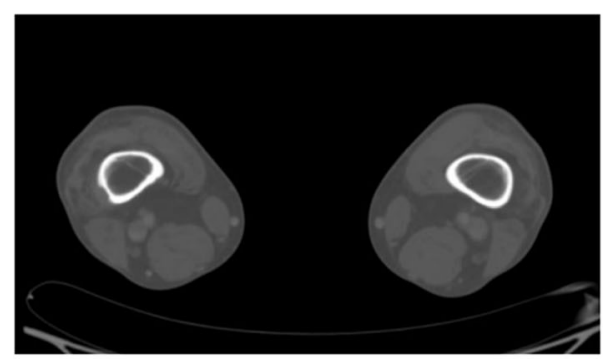

A.

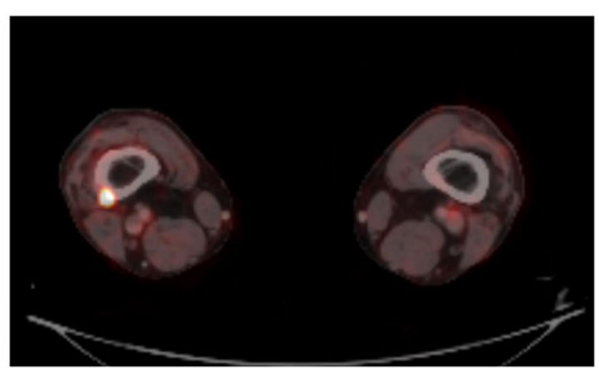

B.

Fig. 4 A 58-year-old male patient, pathologically proven having NSCLC, the initial staging of the patient revealed the following: a CECT staged the patient as MO without any distant metastasis and $\mathbf{b}$ PET/CT upstaged the patient to M1b after detection of an osseous lesion in the outer cortex of the right femur metaphysis that showed high FDG uptake (SUV = 28) with an FDG avid soft tissue component

detected by PET/CT only showed no change in the overall staging due to associated distant metastasis.

Regarding the extrathoracic LNs, FDG PET/CT may be used to identify unsuspected metastases. PET/CT may be used to identify metastases in normal-sized lymph nodes $(<$ $1 \mathrm{~cm}$ at CT), as well as in those with a fatty hilum. Nodal uptake of FDG that is higher than the FDG uptake in the blood pool is suspicious for nodal metastases, and nodal uptake of FDG that is higher than the liver uptake of FDG is highly suspicious for nodal metastases [11].

The current study is in keeping with Sahiner and Vural [35], who reported that the use of PET/CT can also reveal metastasis that would otherwise escape detection as lymph nodes. The benefit of combining conventional CT with PET imaging has been estimated to increase the odds of identifying metastasis at those uncommon sites by $5-29 \%$. The four cases detected by $\mathrm{PET} / \mathrm{CT}$ showed no change in the overall staging due to associated liver and bone metastasis.

In the current study, PET-CT changed the plan of treatment in 5 patients. So, we agree with El-Hariri et al. [36] and Subedi et al. [37] who reported the impact of PET/CT on changing the stage of the disease and the treatment strategy with change in the management plan converting some operable patients to being inoperable and vice versa.

The study had several limitations. The relatively smaller sample size compared to other studies on the same topic. Most of cases were presented in the delayed stages of the disease with multiple distant metastasis, so there was no role for surgery in these cases and no need for further diagnostic imaging or histopathological correlation.

\section{Conclusion}

PET/CT is a useful imaging tool in initial staging of the newly diagnosed patients with NSCLC. It is better than CT alone for detection of malignant lesions for accurate staging. It can change the strategy of treatment according to its findings.

\section{Abbreviations}

18F-FDG PET CT: Fluorodeoxyglucose positron emission tomography; CECT: Contrast enhanced computed tomography; LN: Lymph node; NSCLC: Non-small cell lung cancer; TNM: Tumor node metastasis

\section{Acknowledgements}

The authors thank all the study participants for their patience and support.

\section{Authors' contributions}

NMF reviewed the literature, collected and analyzed the data, performed the statistical analysis, wrote and revised the manuscript, and prepared the figures and tables. RZE suggested and developed the research idea, reviewed the literature, analyzed the data, and revised the manuscript. ASS reviewed the literature, analyzed the data, shared in the statistical analysis, and edited the manuscript. All authors read and approved the final manuscript.

\section{Funding}

This study had no funding from any resource.

Availability of data and materials

The datasets used and/or analyzed during the current study are available from the corresponding author on reasonable request.

Ethics approval and consent to participate

Not applicable. This was a retrospective study. We collected the data from the records of the patients and the institutional review board waived the requirement for informed patient consent.

\section{Consent for publication}

Not applicable.

\section{Competing interests}

The authors declare that they have no competing interests.

Received: 14 October 2019 Accepted: 18 November 2019

Published online: 10 December 2019

\section{References}

1. Nair A, Klusmann MJ, Jogeesvaran KH, Grubnic S, Green SJ, Vlahos I (2011) Revisions to the TNM staging of non-small cell lung cancer: rationale, clinicoradiologic implications, and persistent limitations. Radiographics 31: 215-238

2. Konishi J, Yamazaki K, Tsukamoto E, Tamaki N, Onodera Y, Otake T, Nishimura M (2003) Mediastinal lymph node staging by FDGPET in patients with non-small cell lung cancer: analysis of false-positive FDG-PET findings. Respiration 70:500-506

3. Kelsey CR, Marks LB, Hollis D, Hubbs JL, Ready NE, D'Amico TA, Boyd JA (2009) Local recurrence after surgery for early stage lung cancer: an 11 year experience with 975 patients. Cancer 115:5218-5227 
4. Zhang LP, Wang RW, Deng B, Zhou J, Zheng MA, Kang P (2016) Value of 18F-FDG PET/CT for diagnosis of lymphatic metastasis in patients with nonsmall cell lung cancer. Jreg Anat Oper Surg 3:184-187

5. Chen C (2016) Analysis of the value of multi-slice spiral CT in the screening of high-risk lung cancer and its imaging findings. Chinese J CT MRI 2:42-44

6. Silvestri GA, Gould MK, Margolis ML, Tanoue LT, McCrory D, Toloza E, Detterbeck F. (2007) Noninvasive staging of non-small cell lung cancer: ACCP evidenced-based clinical practice guidelines (2nd edition) Chest:132: 178S-201S.

7. Shim SS, Lee KS, Kim BT, Chung MJ, Lee EJ, Han J, Choi JY, Kwon OJ, Shim YM, Kim S (2005) Non-small cell lung cancer: prospective comparison of integrated FDG PET/CT and CT alone for preoperative staging. Radiology 236:1011-1019

8. Bruzzi JF, Munden RF (2006) PET/CT imaging of lung cancer. J Thorac Imaging. 21:123-136

9. Kim BT, Lee KS, Shim SS, Choi JY, Kwon OJ, Kim H, Kim S (2006) Stage T1 non-small cell lung cancer: preoperative mediastinal nodal staging with integrated FDG PET/CT — a prospective study. Radiology 241:501-509

10. Silvestri GA, Gonzalez AV, Jantz MA, Margolis ML, Gould MK, Tanoue LT, Harris LJ, Detterbeck FC. (2013) Methods for staging non-small cell lung cancer: diagnosis and management of lung cancer, 3rd edn: American College of Chest Physicians evidence-based clinical practice guidelines Chest 143:e211Se250S

11. Kandathil A, Kay FU, Butt YM, Wachsmann JW, Subramaniam RM (2018) Role of FDG PET/CT in the Eighth Edition of TNM Staging of Non-Small Cell Lung Cancer. RadioGraphics 38(7):2134-2149

12. Lardinois D, Weder W, Hany TF, Kamel EM, Korom S, Seifert B, Steinert HC (2003) Staging of non-small-cell lung cancer with integrated positronemission tomography and computed tomography. NEJM 348(25):2500-2507

13. De Wever W, Stroobants S, Coolen J, Verschakelen JA (2009) Integrated PET/ $\mathrm{CT}$ in the staging of non-small cell lung cancer: technical aspects and clinical integration. Eur Respir J 33:201-212

14. Yi CA, Lee KS, Kim B-T, Choi JY, Kwon OJ, Kim H, Shim YM, Chung MJ (2006) Tissue characterization of solitary pulmonary nodule: comparative study between helical dynamic CT and integrated PET/CT. J Nucl Med 47:443-450

15. Halley A, Hugentobler A, Icard P, Porret E, Sobrio F, Lerochais JP, Agostini D (2005) Efficiency of 18F-FDG and 99mTc-depreotide SPECT in the diagnosis of malignancy of solitary pulmonary nodules. Eur J Nucl Med Mol Imaging. 32:1026-1032

16. Acker MR, Burrell SC (2005) Utility of 18F-FDG PET in evaluating cancers of lung. J Nucl Med Technol 33:69-74

17. Ma C, Frosch ZA, Overmoyer B, Cooper AZ (2017) Vocal fold paralysis on positron emission tomography-CT. Thorax 73(1):97-98

18. Steinert HC, Schulthess GK (2011) Initial clinical experience using a new integrated in-line PET/CT system. Br J Radiol 75:S36-S38

19. Darling GE, Maziak DE, Inculet Rl, Gulenchyn KY, Driedger AA, Ung YC, Levine MN (2011) Positron emission tomography-computed tomography compared with invasive mediastinal staging in non-small cell lung cancer results of mediastinal staging in the early lung positron emission tomography trial. J Thorac Oncol 6:1367-1372

20. Perigaud C, Bridji B, Roussel C, Sagan C, Mugniot A, Duveau D, Baron O, Despins P (2009) Prospective preoperative mediastinal lymph node staging by integrated positron emission tomography-computerized tomography in patients with non-small-cell lung cancer. Eur J Cardiothorac Surg 36:731-736

21. Wever W, Ceyssens S, Mortelmans L, Stroobants S, Marchal G, Bogaert J, Verschakelen JA (2007) Additional value of PET-CT in the staging of lung cancer: comparison with CT alone, PET alone and visual correlation of PET and CT. Eur Radiol 17:23-32

22. Jeon TY, Lee KS, Yi CA, Chung MP, Kwon OJ, Kim BT, Shim YM (2010) Incremental value of PET/CT over CT for mediastinal nodal staging of nonsmall cell lung cancer: comparison between patients with and without idiopathic pulmonary fibrosis. Am J Roentgenol 195:370-376

23. Liu BJ, Dong JC, Xu CQ, Zuo CT, Le JJ, Guan YH, Zhao J, Wu JF, Duan XH, Cao YX (2009) Accuracy of 18FFDG PET/CT for lymph node staging in nonsmall-cell lung cancers. Chin Med J 122:1749-1754

24. Yang WF, Tan GZ, Fu Z, Yu JM (2009) Evaluation of the diagnostic value of (18)F-FDG PET-CT and enhanced CT for staging of lymph node metastasis in non-small cell lung cancer. Chin J Oncol 31:925-928

25. Gupta NC, Rogers JS, Graeber GM et al (2002) Clinical role of F-18 fluorodeoxyglucose positron emission tomography imaging in patients with lung cancer and suspected malignant pleural effusion. Chest 122:1918-1924
26. Schaffler GJ, Wolf $G$, Schoellnast $H$ (2004) Non-small cell lung cancer: evaluation of pleural abnormalities on CT scans with 18F FDG PET. Radiol 231:858-865

27. Stroobants S. (2011) PET/CT for staging and diagnosis of lung cancer. In: Luther W. Bradyd,Hans-Peter Heilmann and Michael Molls. Advances in radiation oncology in lung cancer. 2nd edn, Springer,Berlin,Heidelberg 75-87.

28. Fangfang C, Hong Z (2012) PET/CT in the staging of the non-small-cell lung cancer. J Biomed Biotechnol 34:678-786

29. Patricia I, Blanca C, José MG (2011) PET-CT in the staging and treatment of non-small-cell lung cancer. Clin Transl Oncol 13:368-377

30. Wu Y, Li P, Zhang H, Shi Y, Wu H, Zhang J, Yang J (2012) Diagnostic value of fluorine 18 fluorodeoxyglucose positron emission tomography/computed tomography for the detection of metastases in non-small-cell lung cancer patients. Int J Cancer 132(2):E37-E47

31. Schirrmeister $\mathrm{H}$, Arslandemir C, Glatting G, Mayer-Steinacker R, Bommer M, Dreinhfer K, Hetzel ML (2004) Omission of bone scanning according to staging guidelines leads to futile therapy in non-small cell lung cancer. Eur J Nucl Med Mol Imaging 31:964-968

32. Surov A, Hainz M, Holzhausen H-J, Arnold D, Katzer M, Schmidt J (2009) Skeletal muscle metastases: primary tumours, prevalence, and radiological features. Eur Radiol 20:649-658

33. Yilmaz M, Elboga U, Celen Z, Isik F, Tutar E (2011) Multiple muscle metastases from lung cancer detected by FDG PET/CT. Clinical Nuclear Medicine 36(3):245-247

34. Savas K, Pinar KZ, Sevda KS, Ugur K, Evrim S, Halit C, Sevdegul M, Ansal BT (2015) Haematogenous muscular metastasis of non-small cell lung cancer in F-18 fluorodeoxyglucose positron emission tomography/computed tomography. Contemp Oncol (Pozn) 19(3):241-245

35. Sahiner I, Vural GU (2014) Positron emission tomography/computerized tomography in lung cancer. Quant Imaging Med Surg. 4(3):195-206

36. El-Hariri MA, Gouhar GK, Refat AM (2012) Integrated PET/CT in the preoperative staging of lung cancer: a prospective comparison of CT, PET and integrated PET/CT. The Egyptian Journal of Radiology and Nuclear Medicine. 43(4):613-621

37. Subedi N, Scarsbrook A, Darby M, Korde K, Mc Shane P, Muers MF (2009) The clinical impact of integrated FDG PET-CT on management decisions in patients with lung cancer. Lung Cancer 64(3):301-307

\section{Publisher's Note}

Springer Nature remains neutral with regard to jurisdictional claims in published maps and institutional affiliations.

\section{Submit your manuscript to a SpringerOpen ${ }^{\circ}$ journal and benefit from:}

- Convenient online submission

- Rigorous peer review

- Open access: articles freely available online

- High visibility within the field

- Retaining the copyright to your article

Submit your next manuscript at $\boldsymbol{\nabla}$ springeropen.com 